\title{
Vascular Calcification: The Evolving Relationship of Vascular Calcification to Major Acute Coronary Events
}

\author{
H. William Strauss ${ }^{1}$, Takehiro Nakahara ${ }^{2}$, Navneet Narula $^{3}$, and Jagat Narula ${ }^{4}$ \\ ${ }^{1}$ Molecular Imaging and Therapy Service, Memorial Sloan Kettering Cancer Center, New York, New York; ${ }^{2}$ Department of Diagnostic \\ Radiology, Keio University School of Medicine, Tokyo, Japan; ${ }^{3}$ Department of Pathology, New York University School of Medicine, \\ New York, New York; and ${ }^{4}$ Division of Cardiology, Icahn School of Medicine at Mount Sinai, New York, New York
} Learning Objectives: On successful completion of this activity, participants should be able to (1) describe the pathogenesis of atherosclerosis; (2) understand
the importance of the necrotic core in the genesis of microcalcification in the atheroma; and (3) distinguish between the prognostic importance of dense calcification and multiple small foci of calcification adjacent to lipid lakes.

Financial Disclosure: The authors of this article have indicated no relevant relationships that could be perceived as a real or apparent conflict of interest.

CME Credit: SNMMI is accredited by the Accreditation Council for Continuing Medical Education (ACCME) to sponsor continuing education for physicians. SNMMI designates each JNM continuing education article for a maximum of 2.0 AMA PRA Category 1 Credits. Physicians should claim only credit commensurate with the extent of their participation in the activity. For CE credit, SAM, and other credit types, participants can access this activity through the SNMMI website (http://www.snmmilearningcenter.org) through September 2022.

Calcification in a coronary artery is accepted as definite evidence of coronary atherosclerosis. The extent and density of calcification, as combined in the Agatston score, is associated with the risk of a patient experiencing a major acute coronary event. Atherosclerosis occurs because damaged endothelial cells allow low-density lipoprotein cholesterol (LDLC) to leak into subintimal tissue. Proteoglycans in subendothelial collagen have a high affinity for LDLc, retaining the lipoprotein cholesterol complex. As the endothelial damage is repaired, the subintimal LDLC is trapped. Retained LDLC induces an inflammatory response in the overlying endothelium, causing the endothelium to express chemotactic peptides. Chemotactic peptides attract circulating monocytes, which follow the concentration gradient, enter the tissue, and become tissue macrophages to phagocytize and digest the irritating LDLC in the atheroma. In the process of digesting LDLc, enzymes in the macrophages oxidize the LDLc complex. Oxidized LDL is toxic to macrophages; when present in sufficient quantity, it may cause death of macrophages, contributing to inflammation in the atheroma. In a necrotic inflammatory lesion, the regulatory mechanisms that control tissue concentrations of calcium and phosphorus are lost, allowing the solubility product of calcium phosphate to be exceeded, resulting in the formation of microscopic calcium-phosphate crystals. With ongoing inflammation, additional calcium-phosphate crystals are formed, which may aggregate. When these aggregated calcium phosphate crystals exceed $1 \mathrm{~mm}$, the lesions become visible on clinical CT as coronary calcifications. Serial gated CT scans of the heart have demonstrated that once formed, CT-visible calcifications do not decrease significantly in size but may increase.

Key Words: cardiology (clinical); vascular; calcification; coronary artery; coronary atherosclerosis

J Nucl Med 2019; 60:1207-1212

DOI: 10.2967/jnumed.119.230276

Received Apr. 24, 2019; revision accepted Jul. 24, 2019.

For correspondence or reprints contact: H. William Strauss, Memorial Sloan Kettering Cancer Center, 1275 York Ave., Room S-212, New York, NY 10021.

E-mail: harry.strauss@gmail.com

Published online Jul. 26, 2019.

COPYRIGHT (c) 2019 by the Society of Nuclear Medicine and Molecular Imaging.
A lthough dystrophic vascular calcification is a tombstone, it does not identify the lesions likely to cause a major acute coronary event (MACE). Atheromas that are actively undergoing calcification are the most likely to cause MACE, and molecular PET/CT imaging with ionic ${ }^{18} \mathrm{~F}$-fluoride identifies such lesions. Recent data suggest that ${ }^{18} \mathrm{~F}$-fluoride imaging may be a sensitive and specific marker of lesions likely to cause MACE. A multicenter trial is needed to define whether this marker identifies patients at high risk of MACE.

\section{NATURAL HISTORY OF ATHEROMA AND VASCULAR CALCIFICATION}

Vascular calcification can occur in the intima and in the media of arteries. Medial calcification is more common in peripheral vessels and is often associated with elevated levels of calcium or phosphorus, as seen in chronic kidney disease and hyperparathyroidism. Although lesions in the media are palpable at autopsy, they rarely encroach on the vessel lumen (1). On the other hand, intimal calcification is associated with atherosclerosis. Atherosclerosis is a multifocal disease of uncertain etiology characterized by the accumulation of low-density lipoprotein cholesterol (LDLc) beneath the intima of vessels, causing an inflammatory lesion called an atheroma. In patients with persistently elevated circulating levels of LDLc (1), atherosclerosis progresses over decades, with enlargement of existing lesions and formation of new lesions. Atheromas cause single or multiple narrowings of the vascular lumen. A combination of luminal narrowing (with associated turbulence of blood flowing past the irregular surface), may cause local increases in pressure on the vessel wall. If there is a severely inflamed atheroma with a thin fibrous cap separating the necrotic material in the atheroma from the flowing blood, the fibrous cap may rupture (2), releasing thrombogenic material into the vascular lumen, resulting in the formation of a thrombus. If the thrombus is large enough to impede blood flow, it may result in a MACE, such as myocardial ischemia, myocardial infarction, transient ischemic attacks, or stroke. Although the prevalence of atheroma is very high, the incidence of clinical events is extremely low: "On the 
basis of autopsy findings, it is likely that in the game of atheroma roulette fewer than $1 \%$ of atheroma ruptures result in a clinical event." (3)

Despite the low rate of clinical events caused by ruptured atheromas, atherosclerosis is so prevalent that cardiovascular disease accounted for about one third of all deaths in the United States in 2016, with coronary heart disease accounting for 360,000 deaths (4). Despite "major anti-smoking campaigns, medications to control high blood pressure and cholesterol" (5), coronary heart disease remains a major cause of death in middle-aged Americans. To reduce the mortality from coronary disease, multiple approaches have been developed to identify patients at risk for MACE.

Beginning with the Framingham heart study in the 1950s, several clinical and laboratory factors were identified to predict the likelihood that a patient will have a clinical cardiac event. For example, to define the perioperative risk of MACE in patients requiring urgent surgery, the revised cardiac risk index described by Lee et al. (6) is often used as a first step (Table 1). For patients with less urgent needs, there are multiple approaches, including online risk calculators (7) and guidelines to predict the risk that a patient will experience MACE in the next $10 \mathrm{y}$. Patients at high risk are considered for additional clinical and imaging evaluation, such as a high-sensitivity C-reactive protein blood test or a gated, noncontrast CT scan (8) to identify coronary artery calcification as an indication of the burden of coronary artery disease (Figs. 1A and $1 \mathrm{~B})$.

Calcification in an atheroma starts in the inflamed necrotic core. The necrotic core contains a witches' brew of oxidized lipoprotein cholesterol, lipid-laden macrophages (foam cells), and dead and dying macrophages and smooth muscle cells. The histopathology of atheroma demonstrates numerous microcalcifications $2-15 \mu \mathrm{m}$ $(1 \mu \mathrm{m}=0.001 \mathrm{~mm})$ in diameter in areas of necrosis (Figs. 2A-2D). When hyperlipidemia persists, especially in the presence of other cardiovascular risk factors (e.g., smoking, diabetes, and uncontrolled hypertension), the necrotic core enlarges, and both the number and size of the calcifications increase. Before the advent of digital radiography, coronary calcification was detected by cardiologists during x-ray fluoroscopy, where foci of coronary calcification would dance on the screen in synchrony with the patient's heartbeat. Today, coronary artery calcification is identified and quantified on noncontrast, electrocardiography-gated CT. A focus of calcification must be larger than $0.1 \mathrm{~mm}$ to be detected on a

TABLE 1

Revised Cardiac Risk Index (6)

\begin{tabular}{ll}
\hline Factor & \multicolumn{1}{c}{ Description } \\
\hline 1 & High-risk type of surgery (major noncardiac surgery \\
\hline 2 & Ischemic heart disease \\
3 & History of congestive heart failure \\
4 & History of cerebrovascular disease \\
\hline 5 & Preoperative treatment with insulin for diabetes \\
6 & Preoperative serum creatinine $>2.0 \mathrm{mg} / \mathrm{dL}$
\end{tabular}

Rates of major perioperative cardiac complication in patients with $0,1,2$, or 3 or more of these factors were $0.5 \%, 1.3 \%, 4 \%$, and $9 \%$, respectively.

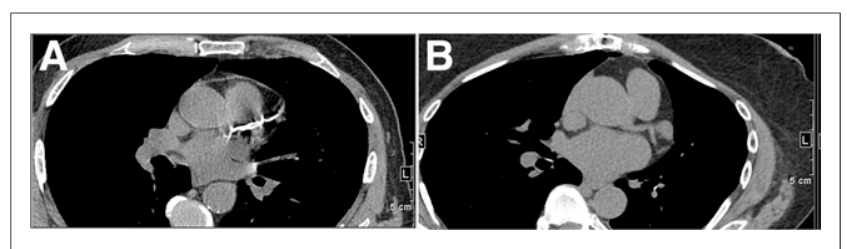

FIGURE 1. Selected gated cardiac CT images of 2 patients. (A) Coronary calcium score of 3,218 . Patient is 70 -y-old male former smoker with family history of CAD. Ammonia perfusion scan demonstrated mediumsized area of moderate ischemia in mid to distal inferolateral wall. In view of extremely high calcium level, amount of ischemia may be underestimated. Ejection fraction was $76 \%$. Stress electrocardiography had significant ST depression in lead 2 and aVf. (B) Coronary calcium score of 0 . Patient is $69-y$-old woman with family history of myasthenia gravis. She presented with increasing dyspnea and chest pain on exertion and had past history of renal cell carcinoma and hypertension.

clinical multidetector CT scan. The focus must also exceed a density of 130 Hounsfield units and have a volume of at least 3 pixels to meet the criteria for a significant calcification. Although several approaches to calculate a coronary calcification score have been developed (9), the scoring system used most often, the Agatston score, combines the density and extent of calcification in each coronary artery into a single score and sums the value to provide a score of the "burden of coronary atherosclerosis" for that patient (10).

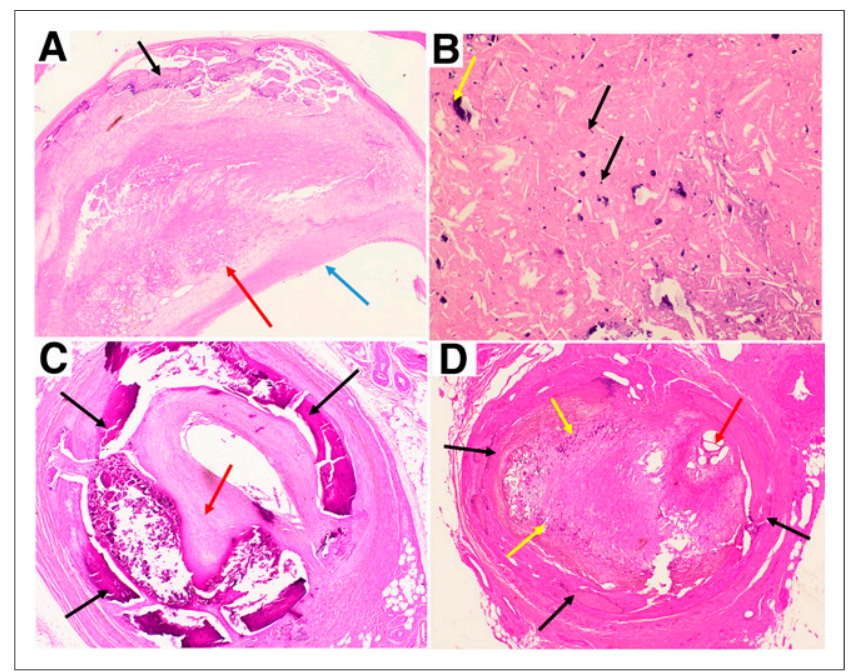

FIGURE 2. (A) Atherosclerotic plaque from carotid endarterectomy specimen has fibroatheromatous plaque with large necrotic core (red arrow), intact fibrous cap (blue arrow), and platelike calcification (black arrow) at base (away from luminal aspect) of plaque at $\times 2$ magnification. (B) Higher magnification $(\times 20)$ of necrotic core of atheromatous plaque from another carotid endarterectomy specimen shows punctate calcification (yellow arrow) and microcalcification (black arrows). (C) Dorsalis pedis artery at $\times 20$ magnification from patient who underwent amputation for critical limb ischemia shows pathologic intimal thickening (red arrow) and medial calcification (black arrows) involving almost entire circumference of artery. (D) Peroneal artery at $\times 20$ magnification from another patient who underwent amputation for critical limb ischemia shows atherosclerotic plaque with punctate calcification (yellow arrows), luminal recanalized thrombus (red arrow), and medial calcification (black arrows). 


\section{EVOLUTION OF ATHEROMA}

In addition to forming a semiselective barrier for retaining macromolecules in the vasculature, vascular endothelium (11) participates in "... immune reactions, vascular repair, and metabolism of bioactive molecules." Under physiologic conditions, endothelial cells serve as a barrier, preventing the LDLc in blood from reaching subintimal tissue. Endothelial cells, however, may be injured by trauma, infection, inflammation, or autoimmune processes. Injured endothelium is permeable to LDLc, allowing the lipoprotein cholesterol complex to come into contact with subendothelial collagen-containing proteoglycans, where it is retained. As the endothelial damage is repaired by adjacent endothelial cells, the subendothelial LDLc is trapped. The cholesterol in trapped LDLc may crystalize (12), causing volume expansion and local inflammation (13). The inflamed endothelial cells express chemotactic peptides $(14,15)$ that attract circulating monocytes to enter the subendothelial tissue. Infiltrating monocytes differentiate into tissue macrophages to phagocytize the lipoprotein-lipid complex. During phagocytosis and digestion of the lipoprotein-bound cholesterol, the macrophages produce enzymes that oxidize the LDLc complex. Oxidized LDLc is toxic to macrophages and, when present in sufficient quantity, cause macrophages to die. Other cells in the atheroma, such as smooth muscle cells, may also die in the intense inflammatory milieu.

Early atheromas show only a low level of inflammation. In this phase, death of macrophages often occurs by organized mechanisms, such as apoptosis (16). When cells die by apoptosis, the remnants of the dead cell are phagocytized by adjacent cells, minimizing residual inflammation in the lesion. In larger, severely inflamed lesions, cells die not only by apoptosis but also

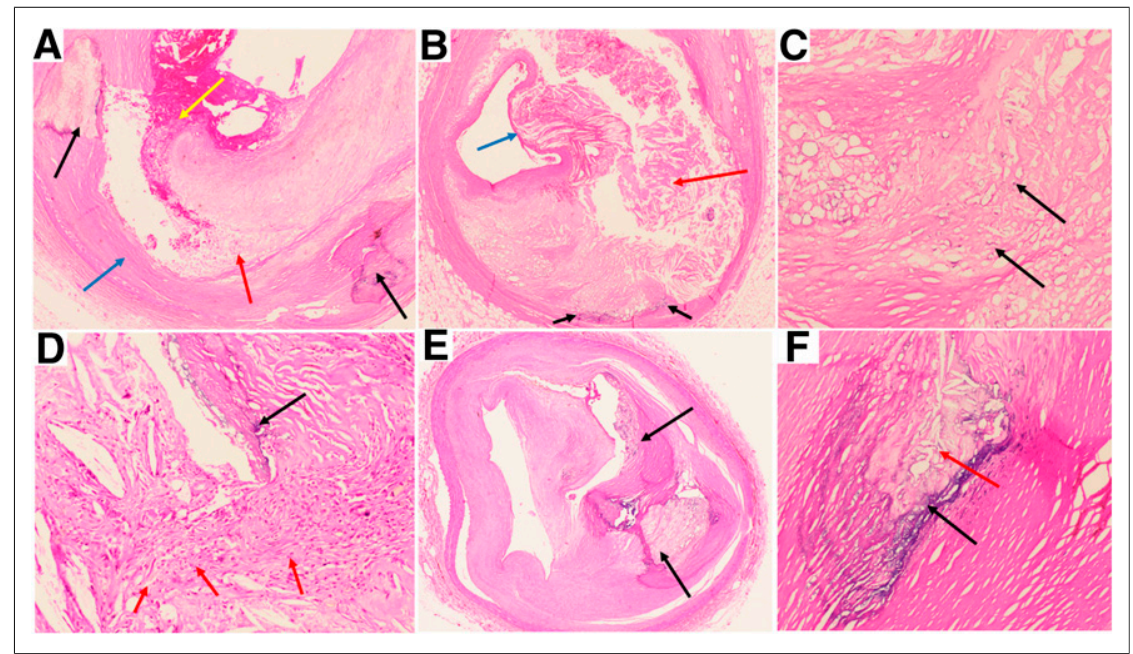

FIGURE 3. (A) Coronary artery showing fibroatheromatous plaque with rupture of fibrous cap (yellow arrow) with acute luminal thrombus that communicates with necrotic core (red arrow) at site of rupture. Deep to necrotic core plaque is fibrosis (blue arrow) with platelike calcification (black arrow). Magnification is $\times 10$. (B) Fibroatheromatous plaque in coronary artery with large necrotic core (red arrow), thin fibrous cap (blue arrow), and punctate calcification at base of plaque (black arrows). Magnification is $\times 4$. ( $C$ and D) Higher magnifications $(\times 20)$ of necrotic core in different atheromatous plaques of coronary arteries that show calcification in necrotic core (black arrows). Plaque in $\mathrm{C}$ is not associated with inflammation, whereas plaque in $D$ is associated with significant inflammation (red arrows). Magnification is $\times 20$. (E) Coronary artery with fibrocalcific plaque. Arrows point to platelike calcium. Magnification is $\times 4$. (F) Higher magnification $(\times 20)$ of plaque shown in image $E$ shows small residual necrotic core (red arrow) in center of predominantly fibrocalcific plaque (black arrow points to microcalcification in the fibrocalcific plaque). by disorganized mechanisms such as necroptosis and necrosis. The latter allow remnants of dead cells to remain in the lesion, increasing inflammation. This type of inefficient cleanup of dead cell remnants, called inefficient efferocytosis (17), adds the detritus of the dead and dying cells to the necrotic core of an atheroma, enlarging the lesion, increasing inflammation, and providing idus for dystrophic calcification (Fig. 3) $(18,19)$. that patients can make to reduce inflammation in atheroma, including exercise, maintaining a normal body mass index, controlling blood patient continues pursuing a proatherogenic lifestyle, however,

\section{FORMATION OF A CALCIFICATION}

In healthy cells, the local concentrations of calcium (20) and phosphorus (21) are tightly regulated, minimizing the possibility of forming unwanted calcium-phosphate crystals. The remnants of dead and dying cells in the necrotic core of an inflamed atheroma, these ions to exceed the solubility product to form calcium phosate crystals. For example, enzymes such as alkaline phosphatase, adenosine triphosphatase, and reactive oxygen species own of larger molecules. Microvesicles (23-25) produced in the process of inflammation, apoptosis, necrotic cell disintegration, and budding of the cell plasma membrane (26) may serve as scaffolding for calcium-phosphate crystal formation (27). Depending on the cells providing the microvesicles, the particles may contain substances that facilitate formation of calcium phosphate crystals or agents that inhibit vascular calcification. When calcium phosphate crystals form in the necrotic core, they may also trap other ions, such as magnesium.

\section{CHARACTERIZATION OF CALCIFICATION}

A noncontrast gated CT scan can be quantified to provide a value that reflects a combination of the extent and density of coronary arterial calcifications $(10,28-30)$. The approximately 2 - to $15-\mu \mathrm{m}$ crystals initially formed in the necrotic core (Fig. 2) are too small to be visible on clinical $\mathrm{CT}$, which has a spatial resolution about $0.6 \mathrm{~mm}$. Over time, in the presence of persistent hyperlipidemia, new microcrystals form in the necrotic core and the microcrystals aggregate. Studies using electronbeam CT almost 3 decades ago and recent studies with noncontrast electrocardiography-gated CT suggested that patients with higher Agatston scores had a greater risk of MACE (31). Recent studies, however, 
suggest that the volume and density of coronary calcification have different prognostic implications (32). A higher-density calcification may reflect lower lipid content or prior subclinical plaque rupture with healing, suggesting that heavily calcified lesions are stable (33) and carry a better prognosis. In contrast, multiple small foci of lower-density calcification, particularly in the region of lipid pools (i.e., spotty or fragmented calcification), suggest a less stable lesion with a higher risk for MACE.

Several large trials, such as the PROSPECT ("Providing Regional Observations to Study Predictors of Events in the Coronary Tree") substudy (34), also reported that culprit lesions contained less calcium than stable lesions, supporting the observation that dense calcification is associated with lesion stabilization (35).

In the lab, the stability of an atheroma can be evaluated by mechanical stress analysis (36). For instance, proximity of a rigid inclusion (microcalcification) to a compliant inclusion (lipid, usually in the necrotic core) near the surface of an atheroma enlarges the area of increased wall stress compared with the deposition of either inclusion alone (37). Other factors influencing the stress on the cap of an atheroma include where the rigid inclusion is located (near the surface or deep in the lesion), the size of the rigid inclusion (calcification), whether there is a single calcification or multiple calcific foci near each other, and the orientation of the foci with reference to the direction of blood flow.

Most microcalcifications in an atheroma occur near dead or dying macrophages, deep in the necrotic lipid core, rarely with inclusion in the fibrous cap (where the increased stress can lead to plaque rupture).

Using a high-resolution laboratory CT scanner to determine the number of calcifications in human coronary artery specimens, investigators observed thousands of microcalcifications $(97 \%$ of them $<0.2 \mathrm{~mm})$ in 62 coronary artery fibroatheromas, with 81 microcalcifications in the fibrous cap of 9 atheromas (38). Threedimensional finite element analysis showed that peak circumferential stress on the fibrous cap of atheromas could increase 5-fold if 2 microcalcifications in the cap were a critical distance from each other and oriented along the tensile axis of blood flow; this level of stress would be more than sufficient to rupture the cap. On the other hand, when the microcalcifications were located within the viscous necrotic core, separated from the cap, the calcific foci were not likely to increase shear stress on the cap (39).

\section{STABILITY OF CALCIFICATION}

Macroscopic coronary artery calcifications are irreversible. They are the end result of a pathologic process due to dysregulated or inappropriate stimuli (40). Whether the calcification is active or passive is unclear (41).

Serial CT measurements have shown that calcifications either are stable or increase over time $(42,43)$. (Although some studies have reported a slight decrease in calcification in some lesions, these small reductions are likely due to technical factors, rather than a real reduction in the amount of calcium at the site (42).) Persistence of calcification is also supported by a long-term animal study wherein monkeys first received an atherogenic diet followed by prolonged feeding of a diet aimed at the regression of atherosclerosis (44). Histopathologic examination of the coronary arteries in animals killed during the atherogenic diet phase demonstrated intra- and extracellular calcium particles, usually adjacent to large lipid pools. Animals killed 3.5 y later, after completing the atherosclerosis regression diet, had regions of calcification in the absence of lipid pools, supporting the concept that calcifications do not regress.

\section{MECHANISMS TO LIMIT VASCULAR CALCIFICATION}

Under physiologic conditions, multiple factors inhibit or prevent $(45,46)$ macroscopic vascular calcification.

\section{Fetuin A (a 59-kDa Glycoprotein}

This glycoprotein, produced by the liver, binds small calcium phosphate crystals and forms calciprotein particles that are phagocytized by macrophages.

\section{Osteocalcin}

This vitamin $\mathrm{K}$-dependent matrix protein, produced by osteoblasts, inhibits apatite crystal growth.

\section{Matrix y-Carboxyglutamate Gla Protein (MGP)}

This 14-kDa protein absorbs crystalline calcium phosphate. Both osteocalcin and MGP require activation by vitamin K (47). MGP is synthesized by vascular smooth muscle cells, chondrocytes, endothelial cells, and fibroblasts and is secreted locally. MGP binds calcium phosphate by chelating calcium and phosphate ions, as well as crystals (46). When vitamin $\mathrm{K}$ levels are reduced or absent, MGP remains inactive, as do other clotting factors such as prothrombin and factors VII, IX, and X $(48,49)$. The vitamin $\mathrm{K}$ antagonist warfarin (Coumadin; Bristol-Myers Squibb) inhibits vitamin $\mathrm{K}$ activation by inhibiting the vitamin $\mathrm{K}$ epoxide reductase complex 1 . In the absence of active vitamin $\mathrm{K}$, these important substances to limit vascular calcification are inactive, resulting in a surprising and undesirable increase in vascular calcification as seen in patients treated with coumadin. In a 66-patient randomized trial comparing changes in coronary artery calcification in patients with atrial fibrillation treated with warfarin versus apixaban (50), the calcified and low-attenuation plaque volume was higher in the group randomized to warfarin than in the apixaban group. Similarly, an analysis of 8 prospective randomized trials using intravascular ultrasound demonstrated a significant increase in the annualized calcium index of patients treated with warfarin compared with those without warfarin (51).

\section{AGING AND VASCULAR CALCIFICATION}

Aging contributes to both increased stiffness of conduit arteries (52) and increased atherosclerosis (53). Aging occurs, in part, because adult cells are not immortal. Hayflick and Moorhead (54) demonstrated that normal human diploid cells have a limited capacity to replicate in vitro ( $\sim 40$ generations). At the end of their reproductive capacity, the final generation of cells is not replaced. This limitation is possibly due in part to the reduction in the length of telomeres with each division. With age, there is also a gradual increase in collagen and a decrease in elastin in the major conduit vessels. Part of the elastin decrease is due to a "fatigue failure" (55) due to the repeated expansion and contraction of conduit vessels with each heartbeat. Age is associated with an increase in the risk for coronary artery disease in the absence of risk factors such as a history of smoking, hypertension, hyperlipidemia, or glucose intolerance (56). Advanced age is also associated with "vessel dilatation, wall thickening, reorganization of cellular and extracellular matrix and an increase in subintimal space due to the accumulation of collagen and mononuclear cells" (56). The extracellular matrix is rich in glycosaminoglycans, which retain LDLc, which penetrates the more permeable, senescent $(57,58)$ endothelial cells $(59)$. 
Therapy with statins decreases circulating levels of LDLc but may paradoxically also increase coronary vascular calcification (60), probably by stabilizing atheromas. Lower levels of circulating LDLc effectively decrease subintimal lipid accumulation, resulting in reduced inflammation, a decreased size of the necrotic core, and possibly increased calcification of the necrotic core.

\section{POTENTIAL ROLE OF MOLECULAR IMAGING}

Identifying patients at risk of sudden death remains a major challenge (5). A 2014 editorial (61) summarized information from multiple studies relating MACE to imaging findings using both invasive intravascular ultrasound and optical coherence tomography, as well as contrast-enhanced CT imaging. Positive predictive values in these imaging studies ranged from $4 \%$ to $22 \%$, which is not sufficient to promulgate a percutaneous intervention (such as stenting) in an asymptomatic patient (even if there is a low risk of adverse events). A test with a much higher positive predictive value would be much more compelling to advocate treating a patient with no symptoms (62).

Several molecular imaging techniques have been proposed to localize and characterize atheroma (62), including radiolabeled autologous LDLc (63), radiolabeled antibodies recognizing oxidized LDLc (64), radiolabeled somatostatin receptor antagonists (to image somatostatin receptors expressed by inflamed atheroma) (65), radiotracers localizing in hypoxic atheroma (66), ${ }^{18} \mathrm{~F}-\mathrm{FDG}$ (67) to identify focal vascular inflammation, and recently, imaging with ${ }^{18}$ F-fluoride $(68)$ to identify active calcification. Although ${ }^{18} \mathrm{~F}$-FDG localizes in the carotid arteries of patients with symptomatic carotid disease, it remains unclear whether ${ }^{18} \mathrm{~F}-\mathrm{FDG}$ coronary arterial uptake correlates with coronary events (69). In a direct comparison of ${ }^{18} \mathrm{~F}$-FDG to ${ }^{18} \mathrm{~F}$-sodium fluoride in patients with myocardial infarction and stable angina, "NaF showed substantially higher uptake in the culprit plaque (70)." ${ }^{18} \mathrm{~F}$-fluoride imaging demonstrated high sensitivity for detecting high-risk lesions that did not concentrate ${ }^{18} \mathrm{~F}$-FDG but demonstrated high-risk plaque characteristics by optical coherence tomography, CT, and intravascular ultrasound (71). Vascular ${ }^{18} \mathrm{~F}$-fluoride uptake also correlated with the presence of microvessels seen on optical coherence tomography, suggesting that ${ }^{18} \mathrm{~F}$-fluoride-avid lesions had increased inflammation. It is conceivable that ${ }^{18} \mathrm{~F}$-fluoride imaging may offer the positive predictive value required to consider therapy in patients at high risk for MACE in the absence of clinical symptoms. This question would have to be addressed in a prospective multicenter study.

\section{CONCLUSION}

Coronary artery calcification seen on noncontrast CT indicates the presence of atherosclerosis. Lesions demonstrating spotty calcification in regions with adjacent pools of lipid are more likely to be unstable. On the other hand, if the calcifications are dense and platelike, especially in the absence of adjacent lipid pools, the CT findings suggest stable lesions. PET/CT imaging using ${ }^{18} \mathrm{~F}-$ sodium fluoride can detect active calcium deposition at multiple vascular beds on a single scan, suggesting that whole-body scans can identify high-risk lesions in multiple beds.

\section{ACKNOWLEDGMENTS}

We thank Heiko Schoder, MD, for his editing suggestions and his contribution of the CT images and clinical descriptions of the data in Figures $1 \mathrm{~A}$ and $1 \mathrm{~B}$.

\section{REFERENCES}

1. Schoen FJ. Blood vessels. In: Kumar V, Abbas AK, Fausto N, eds. Pathologic Basis of Disease. 7th ed. Philadelphia, PA: Elsevier Saunders; 2005:511-554.

2. Narula J, Garg P, Achenbach S, Motoyama S, Virmani R, Strauss HW. Arithmetic of vulnerable plaques for noninvasive imaging. Nat Clin Pract Cardiovasc Med. 2008; $\operatorname{Aug}(5$ suppl 2):S2-S10.

3. Strauss HW, Narula J. Atheroma roulette. J Nucl Cardiol. 2007;14:293-297.

4. Benjamin EJ, Muntner P, Alonso A, et al. Heart disease and stroke statistics: 2019 update-a report from the American Heart Association. Circulation. 2019;139:e56-e528.

5. McKay B. Heart disease roars back. Wall Street Journal. 2019;273:A1, A11.

6. Lee TH, Marcantonio ER, Mangione CM, et al. Derivation and prospective validation of a simple index for prediction of cardiac risk of major noncardiac surgery. Circulation. 1999;100:1043-1049.

7. Heart risk calculator. Symcat blog website. www.cvriskcalculator.com. Last updated November 21, 2017. Accessed August 5, 2019.

8. The asymptomatic patient: risk factor score or calcium score? American College of Cardiology website. https://www.acc.org/latest-in-cardiology/articles/2018/07/ 20/08/46/the-asymptomatic-patient. Published July 20, 2018. Accessed August 5, 2019.

9. Malguria N, Zimmerman S, Fishman EK. Coronary artery calcium scoring: current status and review of the literature. J Comput Assist Tomogr. 2018;42:887-897.

10. Agatston AS, Janowitz WR, Hildner FJ, et al. Quantification of coronary artery calcium using ultrafast computed tomography. J Am Coll Cardiol. 1990;15:827832.

11. Fang Y, Wu D, Birukov KG. Mechanosensing and mechanoregulation of endothelial cell functions. Compr Physiol. 2019;9:873-904.

12. Janoudi A, Shamoun FE, Kalavankunta JK, Abela GS. Cholesterol crystal induced arterial inflammation and destabilization of atherosclerotic plaque. Eur Heart J. 2016;37:1959-1967.

13. Karasawa T, Takahashi M. Role of NLRP3 inflammasomes in atherosclerosis. J Atheroscler Thromb. 2017;24:443-451.

14. Libby P. The vascular biology of atherosclerosis. In: Zipes DP, Libby P, Bonow RO, Braunwald E, eds. Braunwald's Heart Disease. 7th ed. Philadelphia, PA: Elsevier Saunders; 2005:921-937.

15. Ohtsuki K, Hayase M, Akashi K, Kopiwoda S, Strauss HW. Detection of monocyte chemoattractant protein-1 receptor expression in experimental atherosclerotic lesions: an autoradiographic study. Circulation. 2001;104:203-208.

16. Kolodgie FD, Petrov A, Virmani R, et al. Targeting of apoptotic macrophages and experimental atheroma with radiolabeled annexin V. Circulation. 2003;108:3134 3139.

17. Tabas I. Macrophage death and defective inflammation resolution in atherosclerosis. Nat Rev Immunol. 2010;10:36-46.

18. Doherty TM, Asotra K, Fitzpatrick LA, et al. Calcification in atherosclerosis: bone biology and chronic inflammation at the arterial crossroads. Proc Natl Acad Sci USA. 2003;100:11201-11206.

19. Aikawa E, Nahrendorf M, Figueiredo JL, et al. Osteogenesis associates with inflammation in early-stage atherosclerosis evaluated by molecular imaging in vivo. Circulation. 2007;116:2841-2850.

20. Sakamoto A, Virmani R, Finn AV. Coronary artery calcification: recent developments in our understanding of its pathologic and clinical significance. Curr Opin Cardiol. 2018;33:645-652.

21. Srivaths PR, Goldstein GL, Krishnamurthy R, Silverstein DM. High serum phosphorus and FGF 23 levels are associated with progression of coronary calcifications. Pediatr Nephrol. 2014;29:103-109.

22. Bailey G, Meadows J, Morrison AR. Imaging atherosclerotic plaque: translating biology. Curr Atheroscler Rep. 2016;18:51-64.

23. Alique M, Ramirez-Carracedo R, Bodega G, Carracedo J, Ramirez R. Senescent microvesicles: a novel advance in molecular mechanisms of atherosclerotic calcification. Int J Mol Sci. 2018;19:E2003.

24. Durham AL, Speer MY, Scatena M, Giachelli CM, Shanahan CM. Role of smooth muscle cells in vascular calcification: implications in atherosclerosis and arterial stiffness. Cardiovasc Res. 2018;114:590-600.

25. Azoidis I, Cox SC, Davies OG. The role of extracellular vesicles in biomineralization: current perspective and application in regenerative medicine. J Tissue Eng. 2018;9:2041731418810130.

26. Bakhshian Nik A, Hutcheson JD, Aikawa E. Extracellular vesicles as mediators of cardiovascular calcification. Front Cardiovasc Med. 2017;4:78.

27. Shanahan CM. Inflammation ushers in calcification. Circulation. 2007;116: 2782-2785.

28. Thompson RC, Allam AH, Lombardi GP, et al. Atherosclerosis across 4000 years of human history: the Horus study of four ancient populations. Lancet. 2013;381:1211-1222. 
29. Achenbach S, Daniel WG. Computed tomography of the heart. In: Zipes DP, Libby P, Bonow RO, Braunwald E, eds. Braunwald's Heart Disease. 7th ed. Philadelphia, PA: Elsevier Saunders; 2005:355-371.

30. Osawa K, Nakanishi R, Budoff M. Coronary artery calcification. Glob Heart. 2016;11:287-293.

31. Hecht HS. Coronary artery calcium scanning: past, present and future. JACC Cardiovasc Imaging. 2015;8:579-596.

32. Thomas IC, Forbang NI, Criqui MH. The evolving view of coronary artery calcium and cardiovascular disease. Clin Cardiol. 2018;41:144-150.

33. Criqui $\mathrm{MH}$, Denenberg JO, Ix JH, et al. Calcium density of coronary artery plaque and risk of incident cardiovascular events. JAMA. 2014;311:271-278.

34. Xu Y, Mintz GS, Tam A. Prevalence, distribution, predictors, and outcomes of patients with calcified nodules in native coronary arteries: a 3-vessel intravascular ultrasound analysis from Providing Regional Observations to Study Predictors of Events in the Coronary Tree (PROSPECT). Circulation. 2012;126: 537-545.

35. Badimon L, Vilahur G. Thrombosis formation on atherosclerotic lesions and plaque rupture. J Intern Med. 2014;276:618-632.

36. Vengrenyuk Y, Carlier S, Xanthos S, et al. A hypothesis for vulnerable plaque rupture due to stress-induced debonding around cellular microcalcifications in thin fibrous caps. Proc Natl Acad Sci USA. 2006;103:14678-14683.

37. Hoshino T, Chow LA, Hsu JJ, et al. Mechanical stress analysis of a rigid inclusion in distensible material: a model of atherosclerotic calcification and plaque vulnerability. Am J Physiol Heart Circ Physiol. 2009;297:H802-H810.

38. Maldonado N, Kelly-Arnold A, Vengrenyuk Y, et al. A mechanistic analysis of the role of microcalcifications in atherosclerotic plaque stability: potential implications for plaque rupture. Am J Physiol Heart Circ Physiol. 2012;303:H619H628.

39. Mintz GS. Intravascular imaging of coronary calcification and its clinical implications. JACC Cardiovasc Imaging. 2015;8:461-471.

40. Amman K. Media calcification and intima calcification are distinct entities in chronic kidney disease. Clin J Am Soc Nephrol. 2008;3:1599-1605.

41. Panh L, Lairez O, Ruidavets JB, Galinier M, Carrié D, Ferrières J. Coronary artery calcification: from crystal to plaque rupture. Arch Cardiovasc Dis. 2017;110: $550-561$.

42. Henein MY, Koulaouzidis G, Granåsen G, Wiklund U, Guerci A, Schmermund A. The natural history of coronary calcification: a meta-analysis from St Francis and EBEAT trials. Int J Cardiol. 2013;168:3944-3948.

43. Stary HC. Natural history of calcium deposits in atherosclerosis progression and regression. Z Kardiol. 2000;89(suppl 2):28-35.

44. Stary HC. The development of calcium deposits in atherosclerotic lesions and their persistence after lipid regression. Am J Cardiol. 2001;88:16E-19E.

45. Evrard S, Delanaye P, Kamel S, Cristol JP, Cavalier E; SFBC/SN Joined Working Group on Vascular Calcifications. Vascular calcification: from pathophysiology to biomarkers. Clin Chim Acta. 2015;438:401-414.

46. Nakahara T, Dweck MR, Narula N, Pisapia D, Narula J, Strauss HW. Coronary artery calcification: from mechanism to molecular imaging. JACC Cardiovasc Imaging. 2017;10:582-593.

47. Brandenburg VM, Schurgers LJ, Kaesler N, et al. Prevention of vasculopathy by vitamin K supplementation: can we turn fiction into fact? Atherosclerosis. 2015;240:10-16.

48. Siltari A, Vapaatalo H. Vascular calcification, vitamin K and warfarin therapy: possible or plausible connection? Basic Clin Pharmacol Toxicol. 2018;122:1924.

49. Poterucha TJ, Goldhaber SZ. Warfarin and vascular calcification. Am J Med. 2016;129:635.e1-e4
50. Win TT, Nakanishi R, Osawa K, et al. Apixaban versus warfarin in evaluation of progression of atherosclerotic and calcified plaques (prospective randomized trial). Am Heart J. 2019;212:129-133.

51. Andrews J, Psaltis PJ, Bayturan O, et al. Warfarin use is associated with progressive coronary arterial calcification: insights from serial intravascular ultrasound. JACC Cardiovasc Imaging. 2018;11:1315-1323.

52. Greenwald SE. Ageing of the conduit arteries. J Pathol. 2007;211:157-172.

53. McHugh D, Gil J. Senesence and aging: causes, consequences and therapeutic avenues. J Cell Biol. 2018;217:65-77.

54. Hayflick L, Moorhead PS. The serial cultivation of human diploid cell strains. Exp Cell Res. 1961;25:585-621.

55. O'Rourke MF, Safar ME, Dzau V. The cardiovascular continuum extended: aging effects on the aorta and microvasculature. Vasc Med. 2010;15:461-468.

56. Bilato C, Crow MT. Atherosclerosis and the vascular biology of aging. Aging (Milano). 1996;8:221-234.

57. Tesauro M, Mauriello A, Rovella V, et al. Arterial ageing: from endothelial dysfunction to vascular calcification. J Intern Med. 2017;281:471-482.

58. Oakley R, Tharakan B. Vascular hyperpermeability and aging. Aging Dis. 2014; 5:114-125.

59. Williams KJ, Tabas I. The response to retention hypothesis of early atherogenesis. Arterioscler Thromb Vasc Biol. 1995;15:551-561.

60. Dykun I, Lehmann N, Kälsch H, et al. Statin medication enhances progression of coronary artery calcification: the Heinz Nixdorf recall study. J Am Coll Cardiol. 2016;68:2123-2125.

61. Kaul S, Narula J. In search of vulnerable plaque: is there light at the end of the catheter? J Am Coll Cardiol. 2014;64:2519-2524.

62. Nakahara T, Narula J, Strauss HW. Molecular imaging of vulnerable plaque. Semin Nucl Med. 2018;48:291-298.

63. Lees RS, Lees AM, Strauss HW. External imaging of human atherosclerosis. J Nucl Med. 1983;24:154-156.

64. Tsimikas S. Noninvasive imaging of oxidized low-density lipoprotein in atherosclerotic plaques with tagged oxidation-specific antibodies. Am J Cardiol. 2002;90:22L-27L.

65. Malmberg C, Ripa RS, Johnbeck CB, et al. ${ }^{64} \mathrm{Cu}$-DOTATATE for noninvasive assessment of atherosclerosis in large arteries and its correlation with risk factors: head-to-head comparison with ${ }^{68} \mathrm{Ga}$-DOTATOC in 60 patients. $\mathrm{J} \mathrm{Nucl} \mathrm{Med}$. 2015;56:1895-1900.

66. Mateo J, Izquierdo-Garcia D, Badimon JJ, Fayad ZA, Fuster V. Noninvasive assessment of hypoxia in rabbit advanced atherosclerosis using ${ }^{18} \mathrm{~F}$-fluoromisonidazole positron emission tomographic imaging. Circ Cardiovasc Imaging. 2014; 7:312-320.

67. Osborn EA, Kessinger CW, Tawakol A, Jaffer FA. Metabolic and molecular imaging of atherosclerosis and venous thromboembolism. J Nucl Med. 2017;58: 871-877.

68. Derlin T, Richter U, Bannas P, et al. Feasibility of ${ }^{18} \mathrm{~F}$-sodium fluoride PET/CT for imaging of atherosclerotic plaque. J Nucl Med. 2010;51:862-865.

69. Chowdhury MM, Tarkin JM, Evans NR, et al. ${ }^{18}$ F-FDG uptake on PET/CT in symptomatic versus asymptomatic carotid disease: a meta-analysis. Eur J Vasc Endovasc Surg. 2018;56:172-179.

70. Joshi NV, Vesey AT, Williams MC, et al. ${ }^{18} \mathrm{~F}$-fluoride positron emission tomography for identification of ruptured and high-risk coronary atherosclerotic plaques: a prospective clinical trial. Lancet. 2014;383:705-713.

71. Strauss HW, Narula J. ${ }^{18} \mathrm{~F}$-fluoride imaging and other plaque seeking diagnostic strategies: understanding the reality and setting the ground rules. ... Circ Cardiovasc Imaging. 2017;10:e07110. 